This is the accepted manuscript of the article, which has been published in Midwifery, 2020, 88, 102760. https://doi.org/10.1016/j.midw.2020.102760.

(C) 2020. This manuscript version is made available under the CC-BY-NC-ND 4.0 license

\title{
Mothers' parenting self-efficacy, satisfaction and perceptions of their infants during the first days postpartum
}

Elina Botha, Mika Helminen, Marja Kaunonen, Welma Lubbe, Katja Joronen

\begin{abstract}
Objective: The first aim of this study was to describe mothers' self-efficacy, satisfaction and perceptions when parenting their infants during the first days postpartum. Furthermore, the study aimed to explore the distinct sociodemographic as well as mother and infant related factors that are associated with the above parenting aspects.
\end{abstract}

Design: A descriptive and cross-sectional study design was used.

Setting: Three separate postpartum wards 1-7 days after childbirth in one university level hospital in Finland.

Participants: All mothers who gave birth during March 1st to May 20th, 2019 and filled the inclusion criteria, were invited to participate in this study. A convenience sample of 250 mothers with healthy singleton infants agreed to participate.

Measurements and findings: The following instruments were used: The Parenting Self-Efficacy (PSE) scale, the Evaluation subscale of What Being the Parent of a New Baby is Like-revised (WBPL$\mathrm{R})$ and the Perception of Infant scale. Mothers' parenting self-efficacy and parenting satisfaction were high during the first days postpartum. Age, marital status, education and type of birth were not associated with parenting self-efficacy nor satisfaction. Mothers who were unemployed or working only part-time reported higher scores across all categories of parenting self-efficacy, compared to full time employed mothers $(p<.001)$. A higher number of children $(\geq 3)$ were positively associated with both parenting self-efficacy and satisfaction. Mothers who reported poor breastfeeding initiation success also reported significantly lower scores in parenting selfefficacy and parenting satisfaction across all categories. Mothers' perceptions of their infants' fussiness were not associated with parenting self-efficacy $(p=.113)$ nor parenting satisfaction $(p=$ .091).

Key conclusions and implications for practice: The results of this study can benefit postpartum maternity health care professionals by suggesting factors that could be focused on during the very short period that mothers stay in hospital. Discussing prior mothering experiences, work life before maternity leave, breastfeeding initiation experiences and perception of infant with the mothers after childbirth, may lead to better PSE and PS during the postpartum period.

Keywords: Parenting self-efficacy; parenting satisfaction; perception of infant; postpartum period 


\section{Introduction}

Previous research uses self-efficacy evaluations throughout mothers' parenting experience to determine whether being a mother is enjoyable or not (Coleman and Karraker, 1998). A theory first developed by Bandura (1977) describes how an individual's sense of being able to manage a task effectively and successfully (efficacy) will influence how much effort the mother will put into a given task, such as infant care. It also determines how long she will persist in the face of difficulties. Furthermore, according to Bandura's theory, maternal parental self-efficacy (PSE) develops and increases as the mother succeeds at difficult tasks in infant care. The stronger the perceived efficacy, the more effort the mother will put into infant care. Based on Bandura's work, de Montigny and Lacharité (2005) defined the concept of perceived parental efficacy as "beliefs or judgements a parent holds of their capabilities to organize and execute a set of tasks related to parenting a child". Five vital factors have been identified that build and strengthen self-efficacy. These are previous experience, vicarious experience, verbal persuasion, psychological and affective state (Bandura, 1977, 1997).

Most instruments that measure maternal PSE are based on Bandura's theory (Leahy-Warren and McCarthy, 2011). According to Coleman and Karraker (2000) there are four approaches to measure PSE. The first approach is task-specific parenting, the second approach is domain-specific, the third is domain-general parenting, and fourth, general or trait self-efficacy. The task and domain-specific approaches focuses on mothers' beliefs in their capabilities to complete a specific task within a specific domain, such as feeding the infant. The domain-general parenting measures overall self-efficacy in the parenting role, which are not linked to specific parenting tasks. Bandura (1997) recommended the use of task or domain-specific approaches to measure self-efficacy.

Parenting satisfaction (PS), for its part, is a sense of pleasure and gratification gained from the role as a parent. This includes satisfaction from infant care tasks, learning to know the infant and meeting one's own expectations of being a parent (Pridham and Chang, 1989). A parent's sense of competence builds of all these: parenting efficacy, satisfaction, and interest (Jones and Prinz, 2005; Grady and Karraker, 2017). In addition, PSE and satisfaction are significantly and positively related.

Maternal prenatal self-efficacy seems to predict postnatal efficacy, the mother's ability to care for the infant (Leerkes and Burney, 2007). Positive feelings of the infant and family functioning strengthen PS (Salonen et al., 2014). In addition, Leahy-Warren and McCarthy, (2011) discovered a positive relationship between PSE and the number of children, social support, parenting and marital satisfaction. Several studies indicate that parent education interventions can significantly enhance PSE (Bloomfield and Kendall, 2007; Liyana Amin et al., 2018; Yap et al., 2019). Interestingly PSE increases over time (Elek et al., 2003; Leahy-Warren and McCarthy, 2011; Salonen et al., 2014) in mothers of negatively emotional infants, compared to mothers of less negatively emotional infants (Troutman et al., 2012). 
Parents' belief in their own self-efficacy has been connected to a greater focus on planning, which in turn has led to higher levels of parental satisfaction and therefore greater affective well-being. Parents with stronger self-efficacy beliefs are more likely to plan their actions when caring for the child (Márk-Ribiczey et al., 2016). According to Márk-Ribiczey et al. (2016) mothers with low PSE may have limited access to effective cognitive regulation strategies to adjust their emotional responses. Self-efficacy and cognitive processes are expected to be connected only when they are linked to the same form of environmental demands, while their interplay might affect outcomes even across different domains such as in parenting (Márk-Ribiczey et al., 2016). PSE is negatively affected by maternal stress, anxiety, postpartum depression and attachment insecurity (LeahyWarren and McCarthy, 2011; Kohlhoff and Barnett, 2013). Fatigue may pose a risk for health, wellbeing, parenting satisfaction and sense of competence in the parenting role (Cooklin et al., 2011; Dunning and Giallo, 2012). Tired, criticized and overwhelmed mothers have lower selfefficacy. These mothers feel like their children are demanding and they have little control over situations (Whittaker and Cowley, 2012). Fatigue affects wellbeing, increases stress, anxiety and depression and therefore, lowers parenting efficacy (Giallo et al., 2013). Exhaustion may ultimately lead to the mother's inability to manage sources of parenting stress, which may further lower her sense of competence and self-efficacy in the parenting role. Mothers who are not enjoying parenting may find the role demanding and exhausting, which again, amplifies fatigue. PSE and parental stress are connected, but it is difficult to know whether they play an antecedent, consequential or transactional role (Jones and Prinz, 2005). Similarly, Yap et al. (2019) more recently discovered that mothers' general stress level predicts PSE significantly and the stress of a specific parenting task, such as caring for an excessively crying infant, contributed significantly to the deviation in PSE. In addition, mothers with higher levels of education were predicted to have lower PSE scores than those with primary or secondary education (Yap et al., 2019).

Parental self-efficacy can be challenged by infant characteristics that are perceived as difficult. A fussy, excessively crying, irritable, and poorly sleeping infant, is difficult to care for. Mothers of infants that are difficult to soothe, experience high levels of stress related to the parenting role. The constant negative feedback from their infants reduces their PSE, feelings of competence and satisfaction (Cox and Roos, 2008; Troutman et al., 2012; Oddi et al., 2013; Grady and Karraker, 2017). Mothers of fussy infants seem to have lower domain-specific PSE than do mothers of calmer infants (Troutman et al., 2012). Mothers of infants with negative temperament may be in danger for developing unresponsive parenting methods, not even trying to calm the crying infant (Ghera et al., 2006).

Goldsmith et al. (1987) discussed and inspired research on child/infant temperament for decades. They defined that temperament is an outcome of biological and environmental factors functioning together throughout development. Although, more recent work on temperament suggests a different definition. Pridham et al. (1994) suggested that there are associations between infant temperament and parenting competence, while Jones and Prinz (2005) believed that child temperament and behavior can influence PSE. As an alternative to Goldsmith's et al. (1987) definition Shiner et al. (2012) defined that: "Temperament traits are early emerging basic 
dispositions in the domains of activity, affectivity, attention, and self-regulation, and these dispositions are the product of complex interactions among genetic, biological, and environmental factors across time." (p. 437). However, Kohlhoff and Barnett (2013) found no link between infant behaviour and PSE in their study of 83 first-time mothers.

Interestingly, PSE is high when the infant is fussy, but easily soothed (Leerkes and Crockenberg, 2002; Ghera et al., 2006). Furthermore, the way a mother perceives her infant's soothability, affects her maternal sensitivity. If the infant is easily soothed, the mother is also calm. Parents with higher PSE likely display more effective parenting even if the child is demanding. Increased parenting competence can enhance PSE (Jones and Prinz, 2005). Verhage's et al. (2013) study found different results using a cross-lagged panel model. In this longitudinal study of 616 mothers they did not find support for an effect of infant temperament on PSE, but an effect of PSE on infant temperament. They suggest that in the transition to parenthood, the infant temperament is perceived more demanding by mothers with lower PSE.

The studies mentioned above have examined the factors associated with PSE and PS. Given the short hospital stay and the large quantity of information that is relayed in guidance during this small window of time, this information is key in identifying the factors that can be proven helpful in supporting new mothers to a good start. We were unable to find any current research on the factors that are associated with parenting self-efficacy and parenting satisfaction during the immediate postpartum period, 1-7 days after childbirth. Therefore, the aim of this study was to describe mothers' parenting self-efficacy, satisfaction and perceptions of their infants during the first days postpartum. Furthermore, the aim was to discover the distinct sociodemographic factors as well as mother and infant related factors that are associated with mothers' parenting selfefficacy and parenting satisfaction. The hypothesis was that mothers with fussy infants score lower levels in PSE and PS during the first days postpartum.

\section{Methods}

This was a descriptive and cross-sectional study. A questionnaire measuring PSE, PS and Perception of Infant, was used. The questionnaire also included items about mothers' characteristics such as age, marital status, level of education, employment before maternity leave, number of children, type of birth and breastfeeding initiation success.

\section{Participants}

A convenience sample of 250 Finnish speaking mothers who gave birth in a university level hospital in Finland participated in this study. Primiparous or multiparous mothers of a healthy infant rooming in, were included. Mothers with infants who were treated in the NICU during data collection, mothers with multiple infants or inability to understand Finnish, were excluded. 
The sample size calculation was based on a previous study (Pridham and Chang, 1989), from which the standard deviation (0.98) for the Evaluation subscale was acquired. The focus in this study was to compare differences in PS score (Evaluation subscale) between background characteristics such as education, employment and number of children. The clinically significant difference in PS score was approximated as 0.5. Using factor analysis (alfa $=0.05$, power $=0.80$ ) and assuming equal group sizes we calculated that 61 observations were needed in every group in comparisons. Some of the background variables in our study had four different classes and based onto previous calculation, an approximated total sample size of 250 was needed for reliable comparisons between the background variable classes.

Procedures

The data were collected by a questionnaire during March 1st to May 20th, 2019 in a public, university level hospital with approximately 5000 childbirths annually, on three separate postpartum wards. On these wards, healthy mothers and infants room in, with an average hospital stay of 1-3 days. All mothers who stayed on one of these wards during this time, and filled the inclusion criteria, were given the opportunity to participate in the study. A total of 924 mothers gave birth on these three postpartum wards during this data collection period. The mothers were recruited by midwives working on the postpartum wards. All mothers, who filled the criteria and agreed to participate $(n=250)$, were asked to complete the questionnaire independently at the maternity hospital before discharge. The questionnaire included a total of 75 items and took an average of 20 minutes to complete.

\section{Instruments}

Parenting self-efficacy (PSE) was measured using an instrument based on Bandura's theory (1997). The instrument was developed and tested by Salonen et al. $(2008,2009,2010)$. The PSE instrument is domain-specific, and it includes 27 items measuring different infant care skills. These skills are cognitive skills (11 items) such as "I know how to calm a crying baby", affective skills (seven items) such as "I know what my baby enjoys" and behavioural skills (nine items) such as "I'm able to put my baby to sleep". The instrument has a six-point Likert scale 1 = "strongly disagree" to $6=$ "strongly agree". Total PSE scores were calculated by adding up the scores of all items and dividing the sum by the number of items. In addition, the score for each subcategory was calculated by adding up the scores of all items in the subcategory and dividing the sum by the number of items. In this instrument, higher scores indicate better outcomes. Salonen et al. (2008) used the PSE instrument and reported Cronbach's alpha values of 0.96 for mothers (cognitive 0.91, affective 0.92 and behavioural 0.93 ) and 0.95 for fathers (cognitive 0.88 , affective 0.90 and behavioural 0.90) after childbirth.

Parenting satisfaction (PS) was measured with the Evaluation subscale of the revised questionnaire What Being the Parent of a New Baby is Like (WPBL-R; Pridham and Chang, 1989). The WBPL-R has three distinct subscales: Evaluation (11 items), Centrality ( 8 items), and Life Change (6 items). The Evaluation subscale contains items such as "How well do you know your baby?", "How satisfied are you in being a parent of a new baby?" and "How satisfied are you with baby care tasks?". Centrality contains items about how much the infant, his/her care, or physical health are on the parents' mind. Life Change contains items addressing changes in a parent's 
personal life, self-image, relationships with family members and stressfulness of life. The Evaluation subscale contains 11 items where the mothers responded on a 9-point scale with verbal end anchors, such as $1=$ not at all (satisfied) to $9=$ completely (satisfied). Higher scores indicated more PS. Pridham and Chang (1989) reported alpha values of 0.87 and 0.90 for the Evaluation subscale at one week and one month postpartum, respectively. Salonen et al. (2011) reported total scale internal consistency reliabilities for the Evaluation subscale of 0.89 or higher after childbirth (mothers: 0.89; fathers: 0.89 ) and at six to eight weeks postpartum (mothers: 0.91; fathers: 0.91).

Mothers' perceptions of their infants were measured with the Perception of Infant instrument that uses a five-point scale with verbal end anchors. Perceptions measured include the infant's eating, sleeping, contentment, activity level, clarity of cues, adaptability, soothability and demandingness. For example, soothability can range from "difficult to soothe" to "easily soothed" and demandingness refers to "very demanding to care for" to "easy to care for". This instrument was developed by Salonen et al. (2008). Cronbach's alpha for Perception of infant was 0.85 in previous research (Salonen et al., 2014). In addition, several mother and infant attributes and mothers' evaluation of breastfeeding initiation success, were considered as independent variables (Table 1).

\section{Table 1}

Demographic characteristics of mother and infant $(N=250)$.

\begin{tabular}{|c|c|c|}
\hline \multirow[b]{2}{*}{ Characteristic } & \multicolumn{2}{|c|}{$\begin{array}{l}\text { Participants } \\
(\mathrm{N}=250)\end{array}$} \\
\hline & $\mathrm{n}$ & $\%$ \\
\hline \multicolumn{3}{|l|}{ Age } \\
\hline Under 25 & 31 & 12.4 \\
\hline $25-30$ & 86 & 34.4 \\
\hline $31-35$ & 79 & 31.6 \\
\hline Over 35 & 54 & 21.6 \\
\hline \multicolumn{3}{|l|}{ Marital status } \\
\hline Married / Cohabitating & 238 & 95.6 \\
\hline Single, divorced or separated & 11 & 4.4 \\
\hline \multicolumn{3}{|l|}{ Education } \\
\hline Secondary / Upper Secondary School & 45 & 18.0 \\
\hline Vocational school & 77 & 30.8 \\
\hline University of Applied Sciences & 66 & 26.4 \\
\hline University degree & 62 & 24.8 \\
\hline \multicolumn{3}{|l|}{ Employment } \\
\hline Employed & 161 & 64.4 \\
\hline Part-time employed / Unemployed & 89 & 35.6 \\
\hline \multicolumn{3}{|l|}{ Number of children } \\
\hline First child & 122 & 48.8 \\
\hline Second child & 77 & 30.8 \\
\hline Third child or more & 51 & 20.4 \\
\hline \multicolumn{3}{|l|}{ Gestational weeks of infant } \\
\hline $36-39$ & 71 & 28.4 \\
\hline 40 & 72 & 28.8 \\
\hline 41 & 61 & 24.4 \\
\hline 42 & 46 & 18.4 \\
\hline \multicolumn{3}{|l|}{ Birth } \\
\hline Vaginal & 197 & 78.8 \\
\hline Assisted vaginal & 28 & 11.2 \\
\hline Cesarean section & 25 & 10.0 \\
\hline \multicolumn{3}{|l|}{ Gender of infant } \\
\hline Male & 119 & 52.4 \\
\hline
\end{tabular}




\begin{tabular}{|c|c|c|}
\hline Female & 131 & 47.6 \\
\hline \multicolumn{3}{|c|}{ Partner present at birth } \\
\hline Yes & 245 & 98 \\
\hline No & 5 & 2.0 \\
\hline \multicolumn{3}{|c|}{ Breastfeeding initiation success } \\
\hline Poor & 71 & 28.4 \\
\hline Good & 108 & 43.2 \\
\hline Very good & 66 & 26.4 \\
\hline \multicolumn{3}{|c|}{ Mother's perception of infant } \\
\hline Fussy & 49 & 19.6 \\
\hline Non-fussy & 199 & 79.6 \\
\hline
\end{tabular}

\section{Data analysis}

Data were analyzed with SPSS statistical software for Windows, release 25 (SPSS, Chicago, Illinois). Descriptive statistics included frequencies, percentages, means, medians, $Q_{1}, Q_{3}$ and standard deviations. Total scores for the PSE instrument and WBPL-R Evaluation subscale (PS) were calculated by summing the scores for all items and dividing the sum by the number of items. Higher scores indicated better outcomes. The infants were regarded as fussy, if mothers evaluated them with very low points ( 1 or 2 ) in at least one of all eight items. Comparisons were made between mother characteristics, infant fussiness, PSE and PS. Due to skewed distributions, nonparametric tests were used. Mann-Whitney $U$ tests were used for two group comparisons, and Kruskal Wallis tests were used for three or more group comparisons. PSE and PS were also used as dependent variables in linear regression models, with all the mother characteristic variables (excluding marital status) together with infant fussiness as independent variables. Despite the skewness of PSE scores, the model residuals were normally distributed. However, to obtain reliable model estimates for PS score, it was cubic-transformed.

Ethical considerations

The research protocol was approved by The Regional Ethics Committee of the hospital where the research was carried out (Reference Number: R18188H) and is consistent with the revised Helsinki Declaration of 1975 (updated 10/2013). Following approval from the hospital administration, the data were collected during March 1st to May 20th, 2019. All data is protected in compliance with the EU's General Data Protection Regulation 2016/679 (GDPR). The mothers received written and verbal information and signed consent forms. The questionnaires were thereafter pseudonymized and coded for statistical purposes. The instruments were used with the permission of the copyright holders.

\section{Findings}

\section{Demographic data}

The mean age of mothers was 30.5 years (SD 4.78, range 19-44). Most mothers were married or cohabiting $n=238$ (95.6\%). Almost half of the mothers had secondary, upper secondary or vocational education (48.8\%) and just over half (51.2\%) had a higher university degree. Before maternity leave, 161 mothers (64.4\%) were employed full time and 89 (35.6\%) were either part- 
time employed or unemployed. Almost half of the mothers gave birth to their first child $\mathrm{n}=122$ (48.8\%), 77 (30.8\%) mothers to their second child and 51 (20.4\%) mothers had their third child or more (range 1-11). All infants were born between gestational weeks 36 and 42 . Most (78,8\%) births were normal vaginal births, $11.2 \%$ births were assisted vaginal births (vacuum extraction), and $10 \%$ were cesarean sections. Infants' mean age was 2 days at the time of the data collection (range 0-7 days). Most mothers perceived their infants as calm and easy $n=199$ (79.6\%), but 49 mothers (19.6\%) perceived their 1-7-day old infant as fussy in one or more qualities or traits. Table 1 provides description of all demographic variables.

Factors associated with parenting self-efficacy

A series of statistical analyses were conducted to identify which mother characteristics, perceptions of infant and other factors were associated with PSE, and its cognitive, affective and behavioural skills categories (see Table 2). Mothers' mean scores for PSE after childbirth were 4.97 (SD 0.61 range 3.15-6.00). There was no statistically significant difference in PSE across different age groups of mothers. Marital status and education were not associated with parental selfefficacy. However, mothers who were unemployed or working only part-time recorded higher scores across all categories of PSE, compared to full time employed mothers $(p<.001)$. The number of children were also linked to PSE, with the mothers who had their third child or more having higher scores in PSE across all categories $(p<.001)$. Type of birth was not associated with PSE. Breastfeeding initiation success was associated with PSE. Mothers who reported poor breastfeeding initiation success also reported significantly lower scores in PSE across all categories. Mothers' perceptions of their infants' fussiness were not associated with PSE $(p=.113)$. The results from the multivariable linear regressions showed that employment lost the statistical significance in all models, but number of children and breastfeeding initiation success remained as significant predictors for PSE.

Factors associated with parenting satisfaction

The findings were alike PSE, but for the sake of comparison PS is discussed in a similar format in detail here. Comparisons of mother characteristics, perceptions of infant and other factors were made with the Evaluation subscale of PS. Mothers' mean scores for PS after childbirth were 7.88 (SD 0.73 range 3.18-9.00). Maternal age was not associated with PS, nor were marital status, education or employment before maternity leave or type of birth. The number of children were associated with PS. The mothers of three or more children recorded statistically significantly higher scores on PS $(p<.001)$ than the mothers of one or two children. Additionally, breastfeeding initiation success was associated with PS of mothers. Mothers who reported poor breastfeeding initiation success had significantly lowers scores in PS than mothers who reported good or very good breastfeeding initiation success. Mothers' perceptions of their infants' fussiness were not associated with PS $(p=.091)$. After multivariable linear regression modeling with cubictransformed PS score as the dependent variable, employment was not a significant predictor 
anymore, but the interpretation of number of children and breastfeeding initiation success remained similar than presented in Table 3.

\section{Table 2}

Mother and infant characteristics as associated with maternal perceptions of their infant and maternal self-efficacy.

\begin{tabular}{|c|c|c|c|c|c|c|c|c|c|c|c|c|}
\hline \multirow[t]{2}{*}{ Characteristic } & \multicolumn{3}{|c|}{ Self-Efficacy } & \multicolumn{3}{|c|}{ Cognitive Skills } & \multicolumn{3}{|c|}{ Affective Skills } & \multicolumn{3}{|c|}{ Behavioural Skills } \\
\hline & Md & $\left(Q_{1}\right)$ & $\left(Q_{3}\right)$ & $\mathrm{Md}$ & $\left(Q_{1}\right)$ & $\left(Q_{3}\right)$ & Md & $\left(Q_{1}\right)$ & $\left(Q_{3}\right)$ & Md & $\left(Q_{1}\right)$ & $\left(Q_{3}\right)$ \\
\hline \multicolumn{13}{|l|}{ Mother's age } \\
\hline Under 25 & 5.14 & $(4.66)$ & $(5.62)$ & 5.09 & $(4.81)$ & $(5.72)$ & 4.71 & (3.71) & $(5.00)$ & 5.33 & $(4.88)$ & $(5.88)$ \\
\hline $25-30$ & 4.88 & (4.55) & $(5.27)$ & 5.00 & $(4.72)$ & $(5.45)$ & 4.42 & $(4.00)$ & $(4.85)$ & 5.00 & (4.55) & $(5.66)$ \\
\hline $31-35$ & 5.00 & (4.58) & $(5.48)$ & 5.18 & (4.81) & $(5.72)$ & 4.71 & (4.14) & (5.14) & 5.11 & (4.77) & (5.55) \\
\hline Over 35 & 5.07 & $(4.61)$ & $(5.46)$ & 5.27 & $(4.79)$ & $(5.63)$ & 4.71 & (3.92) & $(5.00)$ & 5.22 & (4.72) & $(5.66)$ \\
\hline Statistical comparison across & $\mathrm{ChSq}=$ & & & $\mathrm{ChSq}=$ & & & $\mathrm{ChSq}=$ & & & $\mathrm{ChSq}=$ & & \\
\hline \multirow[t]{2}{*}{ age groups } & 3.293 & & & 3.184 & & & 3.251 & & & 3.425 & & \\
\hline & $p=.349$ & & & $p=.364$ & & & $p=.354$ & & & $p=.331$ & & \\
\hline \multicolumn{13}{|l|}{ Marital status } \\
\hline Married / Cohabitating & 5.00 & (4.59) & $(5.44)$ & 5.18 & $(4.72)$ & (5.63) & 4.57 & $(4.00)$ & $(5.00)$ & 5.16 & (4.69) & $(5.66)$ \\
\hline Single, divorced or separated & 5.11 & $(4.40)$ & $(5.38)$ & 5.18 & (4.36) & $(5.54)$ & 4.57 & $(4.28)$ & $(5.14)$ & 5.00 & (4.33) & (5.66) \\
\hline Statistical comparison across & $z=-$ & & & $z=-$ & & & $z=-$ & & & $z=-$ & & \\
\hline \multirow[t]{2}{*}{ marital status groups } & 0.310 & & & 0.677 & & & 0.781 & & & 0.615 & & \\
\hline & $p=.757$ & & & $p=.498$ & & & $p=.435$ & & & $p=.539$ & & \\
\hline \multicolumn{13}{|l|}{ Education } \\
\hline Secondary / Upper & 4.75 & (4.27) & (5.25) & 5.00 & $(4.40)$ & (5.45) & 4.28 & (3.85) & (4.96) & 5.11 & $(4.50)$ & $(5.72)$ \\
\hline \multicolumn{13}{|l|}{ Secondary School } \\
\hline Vocational school & 5.11 & (4.63) & $(5.58)$ & 5.27 & $(4.81)$ & (5.68) & 4.71 & $(4.28)$ & (5.14) & 5.23 & (4.77) & (5.77) \\
\hline University of Applied & 4.96 & $(4.74)$ & $(5.46)$ & 5.18 & (4.79) & $(5.63)$ & 4.57 & $(4.10)$ & $(5.14)$ & 5.22 & $(4.88)$ & $(5.66)$ \\
\hline \multicolumn{13}{|l|}{ Sciences } \\
\hline University degree & 4.96 & $(4.50)$ & $(5.29)$ & 5.09 & $(4.81)$ & $(5.54)$ & 4.42 & $(4.00)$ & $(5.00)$ & 5.00 & (4.55) & $(5.34)$ \\
\hline Statistical comparison across & $\mathrm{ChSq}=$ & & & $\mathrm{ChSq}=$ & & & $\mathrm{ChSq}=$ & & & $\mathrm{ChSq}=$ & & \\
\hline \multirow[t]{2}{*}{ education groups } & 5.571 & & & 3.572 & & & 6.757 & & & 5.435 & & \\
\hline & $p=.134$ & & & $p=.312$ & & & $p=.080$ & & & $p=.143$ & & \\
\hline \multicolumn{13}{|l|}{ Employment } \\
\hline Employed & 4.88 & $(4.50)$ & (5.31) & 5.00 & $(4.72)$ & (5.54) & 4.42 & $(4.00)$ & $(5.00)$ & 5.00 & (4.55) & $(5.50)$ \\
\hline Part-time & 5.20 & (4.73) & (5.63) & 5.27 & (4.86) & $(5.72)$ & 4.85 & $(4.28)$ & $(5.28)$ & 5.44 & $(4.88)$ & $(5.88)$ \\
\hline \multicolumn{13}{|l|}{ employed/Unemployed } \\
\hline Statistical comparison across & $z=-$ & & & $z=-$ & & & $z=-$ & & & $z=-$ & & \\
\hline \multirow[t]{3}{*}{ employment groups } & 3.490 & & & 2.759 & & & 3.223 & & & 3.631 & & \\
\hline & $p=$ & & & $p=.006$ & & & $p=.001$ & & & $p=$ & & \\
\hline & $<.001$ & & & & & & & & & $<.001$ & & \\
\hline \multicolumn{13}{|l|}{ Number of children } \\
\hline First child & 4.74 & $(4.30)$ & $(5.07)$ & 4.90 & $(4.43)$ & $(5.27)$ & 4.28 & $(3.85)$ & $(4.71)$ & 4.83 & $(4.44)$ & $(5.33)$ \\
\hline Second child & 5.14 & (4.81) & $(5.55)$ & 5.36 & (4.90) & $(5.72)$ & 4.64 & (4.14) & $(5.10)$ & 5.33 & $(5.00)$ & $(5.77)$ \\
\hline Third child or more & 5.48 & $(5.13)$ & (5.77) & 5.63 & $(5.27)$ & $(5.90)$ & 5.00 & (4.71) & (5.42) & 5.61 & $(5.00)$ & $(5.91)$ \\
\hline Statistical comparison across & $\mathrm{ChSq}=$ & & & $\mathrm{ChSq}=$ & & & $\mathrm{ChSq}=$ & & & $\mathrm{ChSq}=$ & & \\
\hline number of children & 64.649 & & & 60.100 & & & 51.865 & & & 52.371 & & \\
\hline & $p=$ & & & $p=$ & & & $p=$ & & & $p=$ & & \\
\hline & $<.001$ & & & $<.001$ & & & $<.001$ & & & $<.001$ & & \\
\hline Type c & & & & & & & & & & & & \\
\hline Vaginal & 5.07 & $(4.62)$ & $(5.48)$ & 5.27 & $(4.81)$ & $(5.63)$ & 4.57 & $(4.14)$ & $(5.00)$ & 5.22 & $(4.77)$ & $(5.66)$ \\
\hline Assisted vaginal & 4.88 & (4.58) & $(5.00)$ & 4.95 & (4.65) & (5.18) & 4.42 & (4.03) & (4.71) & 4.94 & (4.61) & $(5.22)$ \\
\hline Cesarean section & 4.62 & $(4.40)$ & $(5.48)$ & 4.90 & (4.68) & (5.63) & 4.28 & (3.64) & $(5.21)$ & 4.77 & (4.33) & $(5.72)$ \\
\hline Statistical comparison across & $\mathrm{ChSq}=$ & & & $\mathrm{ChSq}=$ & & & $\mathrm{ChSq}=$ & & & $\mathrm{ChSq}=$ & & \\
\hline type of birth & 5.840 & & & 4.206 & & & 3.027 & & & 7.722 & & \\
\hline & $p=.054$ & & & $p=.122$ & & & $p=.220$ & & & $p=.021$ & & \\
\hline $\begin{array}{l}\text { Breastfeeding initiation } \\
\text { success }\end{array}$ & & & & & & & & & & & & \\
\hline Poor & 4.70 & (4.14) & $(5.11)$ & 4.90 & $(4.45)$ & $(5.36)$ & 4.28 & (3.71) & $(4.71)$ & 4.77 & $(4.22)$ & $(5.33)$ \\
\hline Good & 4.92 & $(4.66)$ & $(5.26)$ & 5.04 & (4.75) & $(5.52)$ & 4.57 & (4.14) & $(5.00)$ & 5.11 & (4.77) & $(5.55)$ \\
\hline
\end{tabular}




\begin{tabular}{|c|c|c|c|c|c|c|c|c|c|c|c|c|}
\hline Very good & 5.40 & (4.96) & $(5.75)$ & 5.54 & $(5.00)$ & $(5.81)$ & 5.00 & (4.28) & $(5.42)$ & 5.66 & (5.16) & $(6.00)$ \\
\hline Statistical comparison across & $\mathrm{ChSq}=$ & & & $\mathrm{ChSq}=$ & & & $\mathrm{ChSq}=$ & & & $\mathrm{ChSq}=$ & & \\
\hline breastfeeding initiation & 33.640 & & & 24.161 & & & 22.601 & & & 39.814 & & \\
\hline success & $\begin{array}{c}p= \\
<.001\end{array}$ & & & $\begin{array}{c}p= \\
<.001\end{array}$ & & & $\begin{array}{c}p= \\
<.001\end{array}$ & & & $\begin{array}{c}p= \\
<.001\end{array}$ & & \\
\hline Mother's perception of infant & & & & & & & & & & & & \\
\hline Non-Fussy & 5.03 & (4.62) & $(5.44)$ & 5.18 & $(4.72)$ & $(5.63)$ & 4.57 & (4.14) & $(5.00)$ & 5.22 & (4.77) & $(5.66)$ \\
\hline Fussy & 4.88 & (4.46) & (5.28) & 5.09 & $(4.72)$ & (5.50) & 4.42 & (3.92) & (5.00) & 5.00 & (4.44) & (5.55) \\
\hline $\begin{array}{l}\text { Statistical comparison across } \\
\text { mother's perception of infant }\end{array}$ & $\begin{array}{c}z=- \\
1.585 \\
p=.113\end{array}$ & & & $\begin{array}{c}z=- \\
0.908 \\
p=.364\end{array}$ & & & $\begin{array}{c}z=- \\
1.078 \\
p=.281\end{array}$ & & & $\begin{array}{c}z=- \\
2.049 \\
p=.040\end{array}$ & & \\
\hline
\end{tabular}

a) Mann-Whitney U tests were used for two group comparisons, Kruskal Wallis tests were used for groups with 2 or more groups.

b) $\mathrm{Md}=$ median, $\mathrm{ChSq}=$ Chi square.

c) A conservative alpha level $(p=<.01)$ was used to identify statistically significant comparisons.

\section{Table 3}

Mother and infant characteristics as associated with maternal perceptions of their infant and maternal parenting satisfaction.

\begin{tabular}{|c|c|c|c|}
\hline \multirow[t]{2}{*}{ Characteristics } & \multicolumn{3}{|c|}{ Parenting Satisfaction (Evaluation Subscale) } \\
\hline & Md & $\left(Q_{1}\right)$ & $\left(Q_{3}\right)$ \\
\hline \multicolumn{4}{|l|}{ Mother's age } \\
\hline Under 25 & 7.90 & (7.36) & (8.45) \\
\hline $25-30$ & 7.90 & (7.29) & (8.36) \\
\hline $31-35$ & 8.00 & (7.63) & (8.36) \\
\hline Over 35 & 8.09 & (7.63) & (8.45) \\
\hline \multirow[t]{2}{*}{ Statistical comparison across age groups } & $\mathrm{ChSq}=2.142$ & & \\
\hline & $p=.543$ & & \\
\hline \multicolumn{4}{|l|}{ Marital status } \\
\hline Married / Cohabitating & 7.95 & $(7.54)$ & (8.36) \\
\hline Single, divorced or separated & 8.00 & (7.45) & (8.36) \\
\hline \multirow[t]{2}{*}{ Statistical comparison across marital status groups } & $z=-0.042$ & & \\
\hline & $p=.967$ & & \\
\hline \multicolumn{4}{|l|}{ Education } \\
\hline Secondary / Upper Secondary School & 7.90 & (7.63) & (8.25) \\
\hline Vocational school & 8.04 & (7.63) & (8.54) \\
\hline University of Applied Sciences & 8.00 & (7.56) & (8.36) \\
\hline University degree & 7.85 & (7.15) & (8.36) \\
\hline \multirow[t]{2}{*}{ Statistical comparison across education groups } & $\mathrm{ChSq}=3.726$ & & \\
\hline & $p=.293$ & & \\
\hline \multicolumn{4}{|l|}{ Employment } \\
\hline Employed & 7.90 & $(7.36)$ & (8.36) \\
\hline Part-time employed / Unemployed & 8.09 & (7.71) & (8.54) \\
\hline \multirow[t]{2}{*}{ Statistical comparison across employment groups } & $z=-2.451$ & & \\
\hline & $p=.014$ & & \\
\hline \multicolumn{4}{|l|}{ Number of children } \\
\hline First child & 7.75 & (7.27) & $(8.25)$ \\
\hline Second child & 8.09 & (7.68) & (8.47) \\
\hline Third child or more & 8.27 & $7.90)$ & (8.54) \\
\hline \multirow[t]{2}{*}{ Statistical comparison across number of children } & $\mathrm{ChSq}=23.802$ & & \\
\hline & $p=<.001$ & & \\
\hline \multicolumn{4}{|l|}{ Type of birth } \\
\hline Vaginal & 8.00 & (7.63) & (8.36) \\
\hline Assisted vaginal & 7.90 & (7.04) & (8.36) \\
\hline Cesarean section & 7.81 & (7.22) & (8.54) \\
\hline \multirow[t]{2}{*}{ Statistical comparison across type of birth } & $\mathrm{ChSq}=1.874$ & & \\
\hline & $p=.392$ & & \\
\hline \multicolumn{4}{|l|}{ Breastfeeding initiation success } \\
\hline Poor & 7.63 & (7.09) & (8.18) \\
\hline Good & 7.95 & (7.68) & (8.36) \\
\hline Very good & 8.36 & (7.81) & (8.63) \\
\hline Statistical comparison across breastfeeding initiation success & ChSq $=24.859$ & & \\
\hline
\end{tabular}




\begin{tabular}{lcc} 
& $\mathrm{p}=<.001$ & \\
Mother's perception of infant & & $(7.63)$ \\
Non-Fussy & 7.00 & $(7.09)$ \\
Fussy & $z=-1,693$ & $(8.36)$ \\
Statistical comparison across mother's perception of infant & $\mathrm{p}=.091$ & \\
\hline
\end{tabular}

Notes: A conservative alpha level $(p=<.01)$ was used to identify statistically significant comparisons.

\section{Discussion}

To our knowledge, this is one of only a few studies to examine the factors that are associated with parenting self-efficacy and parenting satisfaction on the immediate postpartum period, 1-7 days after childbirth. This study found important factors that are associated with PSE and PS, but also factors that are not. Mothers evaluated their PSE and PS high immediately after childbirth. The number of children, previous employment and how successful the mothers feel that breastfeeding initiation is, plays an important role in the first days of being a mother of a new infant. Salonen et al. reported similar results, high overall PSE and PS scores, in 2009 and 2010. They explained their findings with the protective role of the hospital where help is always available, and that realities of caring for an infant were yet to be experienced. High PSE and PS in hospital may be recognized as a positive starting point for motherhood.

This study found that, the more experience in parenthood, the better the mothers' PSE and PS were. Similarly, Bandura (1997) found that an experienced mother has succeeded in parenting tasks before and her sense of efficacy builds from that. Mothers' age was not associated with these factors, but the number of children were linked to both PSE and PS. The mothers who had their third child or more had higher scores in PSE across all categories. Moreover, the mothers of a third child or more recorded statistically significantly higher scores on PS than the mothers of one or two children. Leahy-Warren and McCarthy (2011) also discovered a positive relationship between maternal PSE and the number of children. It is known, that PSE increases over time (Elek et al., 2003; Leahy-Warren and McCarthy, 2011; Salonen et al., 2014). In addition, it increases more, over time, in mothers of fussy or irritable infants, compared to mothers of less irritable infants (Troutman et al., 2012).

Employment did play a part in both PSE and PS among participants of this study. Mothers who were unemployed or working only part-time recorded higher scores in PSE, across all categories, compared to full time employed mothers $(p<.001)$. Even if, in this study context, mothers are entitled to maternity leave that start one month prior to their due date. Today's work life is perceived as hectic and stressful (Havermans et al., 2018) and plays a vital role in young adults' and parents' lives. Leaving this environment for maternity leave and a totally different set of dayto-day tasks, may be the reason that mothers who worked full time scored lower levels in PSE. The change in roles from working woman to mother and full-time workplace to staying at home, is considerable. Another reason may be that more generous family policies, particularly paid time off and child-care subsidies may generate happier mothers (Glass et al., 2016). The mothers may experience staying at home with previous children as a source of satisfaction which reflects on the 
postpartum period of the new addition to the family. Recent research found that mothers with higher levels of education were predicted to have lower PSE scores than those with primary or secondary education (Yap et al., 2019). In our study, education was not associated with either PSE or satisfaction.

Mothers who reported poor breastfeeding initiation success had significantly lower scores in PSE across all categories. These mothers also had significantly lower scores in PS than mothers who reported good or very good breastfeeding initiation success. Numerous studies have shed light on factors affecting breastfeeding self-efficacy (Dennis, 2006; Thorpe et al., 2018), but how the experience of breastfeeding initiation success is associated with PSE is a more unknown area. Hankel et al. (2019) found that successful breastfeeding experience significantly predicted increased maternal PSE. To our knowledge, the link between breastfeeding and PS has not been researched until now. Supporting mothers to initiate and maintain breastfeeding and manage common difficulties, is step five in the World Health Organization's (WHO) Ten Steps to Successful Breastfeeding (2018). To ensure this step in the light of our findings, it is critical that midwives put much effort in breastfeeding initiation success as an experience of the mother. Breastfeeding is central in all guidance after childbirth, and mothers' experience of the early steps of the skill is an important factor in their parenthood. Breastfeeding initiation success seems to play a part in how her motherhood begins.

Emphasizing on the mothers' individual experiences of breastfeeding success in the first days postpartum, can reduce problems and increase the perceptions of breastfeeding self-efficacy on the entire postpartum period (Kılcl et al., 2016). One cohort study showed that postpartum maternity care practices, such as decreasing the exposure to opioid analgesia in birth settings and the use of infant formula on the postpartum ward, may improve breastfeeding success short-term and long-term ( $\mathrm{O}^{\prime}$ Connor et al., 2018). In addition, focused breastfeeding counselling, supporting skin to skin contact, frequent breastfeeding, good positioning of the mother infant dyad, and enhanced involvement of the father, can enable long-term breastfeeding success (Nilsson et al., 2017).

In this study, most mothers (79.6\%) perceived their infants as calm and easy, but 49 (19.6\%) mothers perceived their 1-7-day old infant as fussy in one or more qualities. This is an interesting find, since even though much happens in the first days of an infant's life, mothers can quickly learn to know their infants' temperament. Already in 1979, Bates reported that mothers felt that an infant they see as fussy and hard to calm down is difficult and that an infant they see as contented and soothable is easy. According to Bates' study findings, if the mother rated her infant difficult at 1 month, she continued to think so when the infant was 4-6 months. Some research does state that infant temperament and behavior can influence parenting competence and self-efficacy (Pridham et al., 1994; Jones and Prinz, 2005). Salonen et al. (2014) discovered that positive feelings towards the infant, can strengthen PS. Verhage et al. (2013) associated infant temperament with PSE, suggesting that parent self-efficacy affects infant temperament. Mothers with strong sense of self-efficacy can perceive their infants as calm and easy to care for. In Seifer's 
et al. study (2004), mothers were altogether seen as inaccurate raters of their own infants' behavior. This was explained with the fact that parents constantly seek to understand the meaning of their children's behavior. In this study we hypothesized that fussy infants are associated with lower scores in mothers' PSE and PS. Mothers' perceptions of their infants, fussy or not, were not associated with mothers' PSE nor PS. Therefore, our hypothesis was not supported. However, the ratings of PSE and PS were lower among mothers with perceived fussy infants, but the differences between the groups did not reach statistical significance. This encourages us to conduct a further study with a larger sample in the future. The result may also be explained by the early measuring point for mothers to evaluate their infants. Likewise, Kohlhoff and Barnett (2013) found no link between infant behavior and PSE in a study of maternal self-efficacy predictors in 83 first-time mothers during the first year after childbirth. However, the mothers in this setting had early parenting difficulties, which may affect comparisons to this study.

\section{Recommendations}

The results of this study propose concerns that could be addressed in guidance of mothers after childbirth during their short hospital stay. Professionals play a prominent role in guiding and supporting new mothers, since cross-generational support has diminished (Häggman-Laitila, 2003). Social support from family members is important in empowering mothers after childbirth (Leahy-Warren and McCarthy, 2011; Abdollahpour and Keramat, 2016). New mothers often live far from their own parents, who could offer help and support whenever there is a need. Using digital communication tools, such as video meetings, may be helpful to increase a sense of belonging to family and receive more support during this critical life period. The findings of this research on the factors that are associated with PSE and PS during the first days postpartum can help midwives focus their care on the factors that matters most to create a good start into motherhood. Even though mothers have good PSE and PS while still in hospital, identifying mothers who have a risk for low PSE and PS, may enable continuum of care and support in primary health care after hospital discharge.

Discussing prior mothering experiences, work life before maternity leave, breastfeeding initiation experiences and perception of infant with the mothers on postpartum wards, may lead to better PSE and PS during the postpartum period. Targeting more support to experienced mothers with prior parenting difficulties may increase their PSE, even if the general assumption is that experienced mothers need less guidance. With empathic support, the experience of the very first steps of breastfeeding after childbirth, may label it as successful, despite possible difficulties. The successful experience may lead to better PSE and satisfaction, a good start to a long journey as a mother. Mothers who perceive their infants as fussy already during the hospital stay, could be identified before discharge, to ensure that these mother-infant dyads receive targeted support and have access to 24 -hour help, especially if fussiness erupts into excessive crying. 
Strengths and limitations

Well-validated instruments were used (Pridham and Chang, 1989; Salonen et al., 2008, 2009, 2010), which was a strength and facilitated the results of this study. All three instruments were previously pilot tested with expert panels and parents (Salonen 2010) and showed high internal consistency reliability previously and in this study (Gillis and Jackson, 2002; Polit and Beck, 2006). In this study Cronbach's alpha showed that the instruments reached acceptable reliabilities, $\alpha=$ 0.96 (PSE), $\alpha=0.86$ (Evaluation subscale of PS) and $\alpha=0.87$ (Perception of Infant).

One limitation of this study is that the cross-sectional design does not allow causality to be demonstrated, but it does indicate prevalence and suggests relationships between factors for further research. Another limitation is the measuring point. Alike to this study, previous research showed high level of PSE and PS in mothers a day or two after their infants were born (Salonen et al., 2011). Similarly, Salonen et al. (2009) measured PSE immediately after the infants were born, which is a very early measuring point, especially for first-time mothers. On the one hand, the first days with a new infant can be overwhelming, and evaluating your own motherhood at that point, challenging. But then again, encouraging mothers to consider and focus on the items in both instruments, can be beneficial. It will attract mothers' attention to the task at hand and concentrate on the infant. The third limitation is the range of infant age, 1-7 days. This range is large and may contain mothers or infants who have had complexities during their hospital stay. However, the length of the hospital stay was not a participation criterion and since the mothers and infants with hospital stay longer than the average, were healthy and rooming in the point of data collection, they were also included. Infants' median age was two days at the time of the data collection.

\section{Conclusion}

This study indicates that mothers' parenting self-efficacy and parenting satisfaction were high immediately after childbirth. Mothers' full-time employment before giving birth, having a first child and a perceived poor breastfeeding initiation success were associated with lower parenting self-efficacy. The factors that were associated with lower parenting satisfaction were having a first child and a perceived very poor breastfeeding initiation success. Our findings emphasize the importance of discussing prior mothering experiences and work-life situation before maternity leave as well as supporting a successful initiation of breastfeeding. This study presents new evidence that some infants are perceived as fussy by their mothers already in the first days postpartum.

There is a need for further studies to investigate how mothers' PSE and PS changes and, what factors affect them over time. More research is recommended to investigate the infants who are perceived as fussy, how their crying pattern develops in time, and what can be done to intervene. 


\section{References}

Abdollahpour, S., Keramat, A. 2016. The relationship between perceived social support from family and postpartum empowerment with maternal wellbeing in the postpartum period, Journal of Midwifery and Reproductive Health, 4 (4), 779-787.

Bandura, A., 1997. Self-efficacy: The exercise of control., 1st ed. Freeman and Co, New York.

Bandura, A., 1977. Self-efficacy: Toward a unifying theory of behavioral change. Psychological Review 84, 191-215. https://doi.org/10.1037/0033-295X.84.2.191

Bates, J.E., Freeland, C.A.B., Lounsbury, M.L., 1979. Measurement of infant difficultness. Child development 50, 794-803. https://doi.org/10.1111/j.1467-8624.1979.tb02428.x

Bloomfield, L., Kendall, S., 2007. Testing a parenting programme evaluation tool as a pre- and post-course measure of parenting self-efficacy. Journal of Advanced Nursing 60, 487-493. https://doi.org/10.1111/j.1365-2648.2007.04420.x

Coleman, P.K., Karraker, K.H., 2000. Parenting self-Efficacy among mothers of school-age children: Conceptualization, measurement, and correlates. Family Relations 49, 13-24.

https://doi.org/10.1111/j.1741-3729.2000.00013.x

Coleman, P.K., Karraker, K.H., 1998. Self-efficacy and parenting quality: Findings and future applications. Developmental Review 49, 13-24. https://doi.org///doi-

org.libproxy.tuni.fi/10.1006/drev.1997.0448

Cooklin, A.R., Giallo, R., Rose, N., 2012. Parental fatigue and parenting practices during early childhood: an Australian community survey. Child: Care, Health \& Development 38, 654-664. https://doi.org/10.1111/j.1365-2214.2011.01333.x

Cox, L., Roos, V., 2008. The experiences of first-time mothers with colic infants who seek help from medical professionals. Health SA Gesondheid 13, 4-13.

de Montigny, F., Lacharité, C., 2005. Perceived parental efficacy: concept analysis. Journal of advanced nursing 49, 387-396. https://doi.org/10.1111/j.1365-2648.2004.03302.x

Dennis, C.-L.E., 2006. Identifying predictors of breastfeeding self-efficacy in the immediate postpartum period. Research in Nursing \& Health 29, 256-268. https://doi.org/10.1002/nur.20140

Dunning, M.J., Giallo, R., 2012. Fatigue, parenting stress, self-efficacy and satisfaction in mothers of infants and young children. Journal of Reproductive \& Infant Psychology 30, 145-159.

https://doi.org/10.1080/02646838.2012.693910

Elek, S.M., Hudson, D.B., Bouffard, C., 2003. Marital and parenting satisfaction and infant care selfefficacy during the transition to parenthood: the effect of infant sex. Issues in comprehensive pediatric nursing $26,45-57$.

EU General Data Protection Regulation (GDPR), 2016. Regulation (EU) 2016/679. https://eurlex.europa.eu/legal-content/EN/TXT/PDF/?uri=CELEX:32016R0679

Ghera, M.M., Hane, A.A., Malesa, E.E., Fox, N.A., 2006. The role of infant soothability in the relation between infant negativity and maternal sensitivity. Infant Behavior and Development 29, 289-293. https://doi.org///doi-org.libproxy.tuni.fi/10.1016/j.infbeh.2005.09.003 
Giallo, R., Wood, C.E., Jellett, R., Porter, R., 2013. Fatigue, wellbeing and parental self-efficacy in mothers of children with an Autism Spectrum Disorder. Autism 17, 465-480.

https://doi.org/10.1177/1362361311416830

Gillis, A., Jackson, W., 2002. Research for nurses: methods and interpretation. Davis, Philadelphia.

Glass, J., Simon, R.W., Andersson, M.A., 2016. Parenthood and Happiness: Effects of work-family reconciliation policies in 22 OECD countries. American Journal of Sociology 122, 886-929.

https://doi.org/10.1086/688892

Goldsmith, H.H., Buss, A.H., Plomin, R., Rothbart, M.K., Thomas, A., Chess, S., Hinde, R.A., McCall, R.B., 1987. Roundtable: What Is Temperament? Four Approaches. Child development 58, 505-529. https://doi.org/10.1111/j.1467-8624.1987.tb01398.x

Grady, J.S., Karraker, K., 2017. Mother and child temperament as interacting correlates of parenting sense of competence in toddlerhood. Infant \& Child Development 26, 1-15. https://doi.org/10.1002/icd.1997

Hankel, M.A., Kunseler, F.C., Oosterman, M., 2019. Early Breastfeeding Experiences Predict Maternal Self-Efficacy During the Transition to Parenthood. Breastfeeding Medicine 14, 568-574. https://doi.org/10.1089/bfm.2019.0023

Havermans, B.M., Brouwers, E.P.M., Hoek, R.J.A., Anema, J.R., van der Beek, A.J., Boot, C.R.L., 2018. Work stress prevention needs of employees and supervisors. BMC public health $18,1471-$ 2458. https://doi.org/10.1186/s12889-018-5535-1

Häggman-Laitila, A., 2003. Early support needs of Finnish families with small children. Journal of advanced nursing 41, 595-606. https://doi.org/10.1046/j.1365-2648.2003.02571.x

Jones, T.L., Prinz, R.J., 2005. Potential roles of parental self-efficacy in parent and child adjustment: A review. Clinical Psychology Review 25, 341-363. https://doi.org///doiorg.libproxy.tuni.fi/10.1016/j.cpr.2004.12.004

Kılcı, H., Çoban, A., Kılcı, H., 2016. The correlation between breastfeeding success in the early postpartum period and the perception of self-efficacy in breastfeeding and breast problems in the late postpartum. Breastfeeding Medicine 11, 188-195. https://doi.org/10.1089/bfm.2015.0046

Kohlhoff, J., Barnett, B., 2013. Parenting self-efficacy: Links with maternal depression, infant behaviour and adult attachment. Early Human Development 89, 249-256. https://doi.org///doiorg.libproxy.tuni.fi/10.1016/j.earlhumdev.2013.01.008

Leahy-Warren, P., McCarthy, G., 2011. Maternal parental self-efficacy in the postpartum period. Midwifery 27, 802-810. https://doi.org/10.1016/j.midw.2010.07.008

Leerkes, E.M., Burney, R.V., 2007. The development of parenting efficacy among new mothers and fathers. Infancy 12, 45-67. https://doi.org/10.1111/j.1532-7078.2007.tb00233.x

Leerkes, E.M., Crockenberg, S.C., 2002. The development of maternal self-efficacy and its impact on maternal behavior. Infancy 3, 227-247. https://doi.org/10.1207/S15327078IN0302_7

Liyana Amin, N.A., Tam, W.W.S., Shorey, S., 2018. Enhancing first-time parents' self-efficacy: A systematic review and meta-analysis of universal parent education interventions' efficacy. International Journal of Nursing Studies 82, 149-162. https://doi.org///doiorg.libproxy.tuni.fi/10.1016/j.ijnurstu.2018.03.021 
Márk-Ribiczey, N., Miklósi, M., Szabó, M., 2016. Maternal self-efficacy and role satisfaction: The mediating effect of cognitive emotion regulation. Journal of Child and Family Studies 25, 189-197. https://doi.org/10.1007/s10826-015-0217-4

Nilsson, I.M.S., Strandberg-Larsen, K., Knight, C.H., Hansen, A.V., Kronborg, H., 2017. Focused breastfeeding counselling improves short- and long-term success in an early-discharge setting: A cluster-randomized study. Maternal \& Child Nutrition 13, e12432.

https://doi.org/10.1111/mcn.12432

O’Connor, M., Allen, J., Kelly, J., Gao, Y., Kildea, S., 2018. Predictors of breastfeeding exclusivity and duration in a hospital without Baby Friendly Hospital Initiative accreditation: A prospective cohort study. Women \& Birth 31, 319-324. https://doi.org/10.1016/j.wombi.2017.10.013

Oddi, K.B., Murdock, K.W., Vadnais, S., Bridgett, D.J., Gartstein, M.A., 2013. Maternal and infant temperament characteristics as contributors to parenting stress in the first year postpartum. Infant \& Child Development 22, 553-579. https://doi.org/10.1002/icd.1813

Polit, D.F., Beck, C.T., 2006. Essentials of nursing research: methods, appraisal, and utilization. Lippincott Williams \& Wilkins, Philadelphia.

Pridham, K.F., Chang, A.S., 1989. What being the parent of a new baby is like: revision of an instrument. Research in Nursing \& Health 12, 323-329.

Pridham, K.F., Chang, A.S., Chiu, Y.M., 1994. Mothers' parenting self-appraisals: the contribution of perceived infant temperament. Research in Nursing \& Health 17, 381-392.

Salonen, A.H., Kaunonen, M., Åstedt-Kurki, P., Järvenpää, A., Isoaho, H., Tarkka, M., 2009. Parenting self-efficacy after childbirth. Journal of Advanced Nursing 65, 2324-2336. https://doi.org/10.1111/j.1365-2648.2009.05113.x

Salonen, A.H., Kaunonen, M., Åstedt-Kurki, P., Järvenpää, A., Tarkka, M., 2008. Development of an Internet-based intervention for parents of infants. Journal of Advanced Nursing 64, 60-72. https://doi.org/10.1111/j.1365-2648.2008.04759.x

Salonen, A.H., Kaunonen, M., Åstedt-Kurki, P., Järvenpää, A.-L., Isoaho, H., Tarkka, M.-T., 2011. Effectiveness of an internet-based intervention enhancing Finnish parents' parenting satisfaction and parenting self-efficacy during the postpartum period. Midwifery 27, 832-841. https://doi.org/10.1016/j.midw.2010.08.010

Salonen, A.H., Kaunonen, M., Åstedt-Kurki, P., Järvenpää, A.-L., Isoaho, H., Tarkka, M.-T., 2010. Parenting satisfaction during the immediate postpartum period: factors contributing to mothers' and fathers' perceptions. Journal of Clinical Nursing 19, 1716-1728.

https://doi.org/10.1111/j.1365-2702.2009.02971.x

Salonen, A.H., Pridham, K.F., Brown, R.L., Kaunonen, M., 2014. Impact of an internet-based intervention on Finnish mothers' perceptions of parenting satisfaction, infant centrality and depressive symptoms during the postpartum year. Midwifery 30, 112-122.

https://doi.org/10.1016/j.midw.2013.02.009

Seifer, R., Sameroff, A., Dickstein, S., Schiller, M., Hayden, L.C., 2004. Your own children are special: clues to the sources of reporting bias in temperament assessments. Infant Behavior and Development 27, 323-341. https://doi.org///doi-org.libproxy.tuni.fi/10.1016/j.infbeh.2003.12.005

Shiner, R.L., Buss, K.A., McClowry, S.G., Putnam, S.P., Saudino, K.J., Zentner, M., 2012. What is temperament now? Assessing progress in temperament research on the twenty-fifth anniversary 
of Goldsmith et al. Child Development Perspectives 6, 436-444. https://doi.org/10.1111/j.17508606.2012.00254.x

Thorpe, K., Jansen, E., Cromack, C., Gallegos, D., 2018. Can a call make a difference? Measured change in women's breastfeeding self-efficacy across call interactions on a telephone helpline. Maternal and Child Health Journal 22, 1761-1770. https://doi.org/10.1007/s10995-018-2573-3

Troutman, B., Moran, T.E., Arndt, S., Johnson, R.F., Chmielewski, M., 2012. Development of parenting self-efficacy in mothers of infants with high negative emotionality. Infant Mental Health Journal 33, 45-54. https://doi.org/10.1002/imhj.20332

Verhage, M.L., Oosterman, M., Schuengel, C., 2013. Parenting self-efficacy predicts perceptions of infant negative temperament characteristics, not vice versa. Journal of Family Psychology 27, 844849. https://doi.org/10.1037/a0034263

Whittaker, K.A., Cowley, S., 2012. A survey of parental self-efficacy experiences: maximising potential through health visiting and universal parenting support. Journal of Clinical Nursing 21, 3276-3286. https://doi.org/10.1111/j.1365-2702.2012.04074.x

World Health Organization, 2018. Ten steps to successful breastfeeding. https://www.who.int/nutrition/bfhi/ten-steps/en/

Yap, D.F.-F., Nasir, N., Tan, K.S.M., Lau, L.H.S., 2019. Variables which predict maternal self-efficacy: A hierarchical linear regression analysis. Journal of Applied Research in Intellectual Disabilities 32, 841-848. https://doi.org/10.1111/jar.12575 